\title{
A new Lower Triassic ichthyopterygian assemblage from Fossil Hill, Nevada
}

Neil P Kelley, Ryosuke Motani, Patrick Embree, Michael J Orchard

We report a new ichthyopterygian assemblage from Lower Triassic horizons of the Prida Formation at Fossil Hill in central Nevada. Although fragmentary, the specimens collected so far document a diverse fauna. One partial jaw exhibits isodont dentition with blunt tipped, mesiodistally compressed crowns and striated enamel. These features are shared with the Early Triassic genus Utatsusaurus known from coeval deposits in Japan and British Columbia. An additional specimen exhibits a different dentition characterized by relatively small, rounded posterior teeth resembling other Early Triassic ichthyopterygians particularly Grippia. This Nevada assemblage marks a southward latitudinal extension for Early Triassic ichthyopterygians along the eastern margin of Panthalassa and indicates repeated circum-oceanic dispersal events in Early Triassic ichthyopterygians. 
1 A new Lower Triassic Ichthyopterygian assemblage from Fossil Hill, Nevada

2 NEIL P. KELLEY, ${ }^{*}, 1,2$ RYOSUKE MOTANI, ${ }^{1}$ PATRICK EMBREE, ${ }^{3}$ and MICHAEL J.

3 ORCHARD,${ }^{4}$ Department of Earth and Planetary Sciences, University of California, Davis, 1

4 Shields Avenue, Davis, California, 95616, U.S.A., kelleynp@si.edu; rmotani@ucdavis.edu;

$5{ }^{1}$ Department of Paleobiology, National Museum of Natural History, Smithsonian Institution, PO

6 Box 37012, Washington, DC 20013, USA.; 38834 Central Avenue, Orangevale, CA 95662

7 patembree@aol.com; ${ }^{4}$ Natural Resources Canada - Geological Survey of Canada, 1500-605

8 Robson St., Vancouver, B.C. V6B 5J3, Canada mike.orchard@canada.ca

9

10

11

$12{ }^{*}$ Corresponding author

13

14

15

16

17

18

19

20

21

22

23 
24 Abstract

25 We report a new ichthyopterygian assemblage from Lower Triassic horizons of the Prida

26 Formation at Fossil Hill in central Nevada. Although fragmentary, the specimens collected so far

27 document a diverse fauna. One partial jaw exhibits isodont dentition with blunt tipped,

28 mesiodistally compressed crowns and striated enamel. These features are shared with the Early

29 Triassic genus Utatsusaurus known from coeval deposits in Japan and British Columbia. An

30 additional specimen exhibits a different dentition characterized by relatively small, rounded

31 posterior teeth resembling other Early Triassic ichthyopterygians, particularly Grippia. This

32 Nevada assemblage marks a southward latitudinal extension for Early Triassic ichthyopterygians

33 along the eastern margin of Panthalassa and indicates repeated trans-hemispheric dispersal

34 events in Early Triassic ichthyopterygians.

36 Main article text

37 Introduction

38 Ichthyosaurs were among the most enduring and successful Mesozoic marine reptile groups,

39 appearing in the Early Triassic and persisting some 150 million years until their extinction in the

40 Late Cretaceous (McGowan and Motani, 2003). The fossil record of early ichthyopterygians (the

41 clade comprising ichthyosaurs and close relatives) includes a variety of morphologically

42 disparate taxa from widespread localities in Asia, North America and the Arctic. Most of these

43 assemblages are broadly contemporaneous, all being late Spathian (late Early Triassic) in age.

44 Recent discoveries in China (Ji et al., 2014, Motani et al., 2015) have extended this record

45 earlier into the Spathian and have shed new light on the phylogenetic and biogeographic origins 
46 of the clade. However, the rapid early diversification and trans-hemispheric dispersal history of

47 ichthyopterygians during the Early Triassic remains poorly understood.

49 Nevada has been an important source of Triassic marine reptile fossils since the $19^{\text {th }}$ Century producing abundant and well-preserved Middle Triassic (Leidy, 1868; Merriam, 1905, 1908,

51 1910; Sander et al., 1994, 1997; Fröbisch et al., 2006, 2013) and Late Triassic (Camp 1976, 52 1980) ichthyopterygian and sauropterygian fossils. Notably, Early $20^{\text {th }}$ Century field work led by 53 John Merriam and Annie Alexander at the Fossil Hill locality in the Humboldt Range produced 54 several specimens of the ichthyosaur Cymbospondylus (Merriam 1908)-previously described by 55 Leidy (1868) on the basis of fragmentary remains-as well as the type specimens of Omphalosaurus nevadanus (Merriam, 1906) and Phalarodon fraasi (Merriam 1910). Later work by Camp $(1976,1980)$, Sander et al. $(1994,1997)$ and others illuminated rich Middle and Late

58 Triassic marine reptile assemblages preserved in Nevada.

In contrast, knowledge of Early Triassic marine reptile fossils in this region is scant. The only

61 published Early Triassic marine reptile occurrence from Nevada is based on a partial jaw referred

62 to the enigmatic genus Omphalosaurus and described as a second species, O. nettarhynchus

63 Mazin and Bucher, 1987. This specimen was collected from the Spathian-aged informally

64 designated "lower member" of the Prida Formation in the Humboldt Range, which sits

65 immediately below the well-known Fossil Hill Member of the Prida Formation, famous for its

66 rich marine reptile assemblage including the aforementioned Cymbospondylus, Phalarodon, and

67 Omphalosaurus nevadanus. Fragmentary, float-derived remains of Early Triassic

68 ichthyopterygians have been reported from Spathian horizons in southeastern Idaho (Massare 
69 and Callaway, 1994; Scheyer et al., 2014) roughly $500 \mathrm{~km}$ to the northeast of the Fossil Hill

70 locality. Even further to the east, the early sauropterygian Corosaurus alcovensis Case, 1936 is

71 known from the Alcova limestone in Wyoming whose Early Triassic age was recently confirmed

72 (Lovelace and Doebbert, 2015).

74 Here, we report a new Early Triassic ichthyopterygian assemblage from the lower member of the

75 Prida Formation at the Fossil Hill Locality. These fossils are Spathian (Lower Triassic) in age

76 based on co-occuring conodont and ammonoid faunas and sit stratigraphically below the diverse

77 Middle Triassic marine reptile assemblage from the Fossil Hill Member of the Prida Formation.

78 These occurrences extend the southward latitudinal range of early ichthyopterygians in North

79 America and demonstrate that early in their evolutionary history, multiple ichthyopterygian taxa

80 quickly dispersed around or across wide expanses of ocean and ranged from sub-tropical to high

81 temperate waters on the eastern margin of northern Panthalassa.

82 Institutional Abbreviations. USNM, National Museum of Natural History, Smithsonian

83 Institution, Washington, D.C., U.S.A.

85 Materials and Methods

\section{Geological and Stratigraphic Setting}

87 The new fossils reported here were collected from multiple horizons within the unnamed lower

88 member of the Prida Formation of the Star Peak Group at Fossil Hill, on the eastern flank of the

89 Humboldt Range in Pershing County, Nevada (Fig. 1). The Star Peak Group consists of a

90 sequence of syndepositionally deformed carbonate-dominated units deposited on what was then

91 the western shelf of North America (Nicholls \& Silberling, 1977; Wyld, 2000). In the study area, 
92 the lower member of the Prida Formation forms the base of the Star Peak Group and sits

93 unconformably atop the Permian/Lower Triassic aged Koipato Group volcanics (Wyld, 2000).

95 The lower member of the Prida Formation transitions from siliciclastic sand and conglomerate

96 layers near the contact with the underlying Koipato Group to dark-grey limestone above with

97 intermittent microbialite, conglomerate and chert-dominated beds. The presence of

98 conglomerates and microbialites indicate relatively shallow conditions with a general trend

99 towards deeper water facies characteristic of the overlying Fossil Hill Member (Wyld, 2000).

100 Gastropods and bivalves are abundant in lower layers whereas conodonts and ammonoids are

101 found locally within middle and upper layers of the lower member. Scattered vertebrate fossils

102 occur in multiple horizons within the lower member (Fig. 1), but are most abundant in the middle

103 carbonate layers where they are associated with the conodont Triassospathodus symmetricus

104 (Orchard, 1995) and the ammonoid Prohungarites gutstadti (Guex et al., 2010) indicating a late

105 Spathian age (Subcolumbites ammonoid biozone). These fossils were collected by the landowner

106 and co-author Patrick Embree, who donated the material to the Smithsonian National Museum of

107 Natural History.

108

109 Results

110 Systematic Paleontology

111 Ichthyopterygia Owen, 1840

112 cf. Utatsusaurus Shikama, Kamei and Murata, 1978

113 Diagnosis. Teeth smaller than marginal dentition present on pterygoid; squamosal not entirely

114 eliminated from supratemporal fenestra by supratemporal; interclavicle cruciform; dorsal margin 
115 of external naris formed entirely by nasal; prefrontal shelf prominent; transverse flange of the

116 pterygoid well defined and anterolaterally projecting; supratemporal terrace present; tooth

117 implantation subthecodont, with both dental groove and shallow socket; tooth crowns of middle

118 to posteriorly placed teeth distomesially compressed; humerus as wide proximally as distally;

119 humerus longer than wide; ulnar facet of humerus as wide as radial facet; no more than five

120 phalanges in any digit; posterior dorsal vertebrae cylindrical in outline (from Cuthbertson et al.,

121 2013a; after Motani, 1999; McGowan and Motani, 2003).

122

123 Referred specimen. USNM 559349 Partial mandible including teeth. (Fig. 2)

124 Locality. Fossil Hill, Humboldt Range, Pershing County, Nevada.

125 Horizon and age. Found as surface float within an outcrop of Lower Triassic (upper Spathian)

126 lower member of Prida Formation, Star Peak Group. Based on location and matrix lithology this

127 jaw is inferred to derive from horizon FH1-7 (Fig. 1), which is Spathian based on the occurrence

128 of the ammonoid Prohungarites gutstadi (i.e. Subcolumbites Zone of Guex et al., 2010) and

129 conodonts Triassospathodus symmetricus (Orchard, 1995) and Neostrachanognathus sp.

130 extracted from the matrix.

132 Description. USNM 559349 is a partial mandible measuring $82 \mathrm{~mm}$ long. The jaw fragment 133 preserves portions of the dentary, surangular and splenial. The surfaces of the dentary and

134 surangular are heavily striated and the orientation of these striations differs between the bones.

135 The suture between the dentary and surangular is long and straight, extending across the entire

136 preserved portion of the jaw. In places this suture is indistinct but can be traced by the

137 contrasting surface striation patterns of the dentary and surangular. The splenial can be observed 
138 at the broken anterior edge of the fossil where it comprises the medial and ventral portion of the

139 jaw where a thin projection wraps underneath the surangular. A row of irregular weathered

140 depressions follows the approximate course of the suture between the surangular and dentary but

141 it is not clear if these represent natural foramina or are simply artifacts of weathering. Judging

142 from the arrangement of the bones, the fragment likely represents a central-posterior portion of

143 the left mandibular ramus anterior to the coronoid process.

145 Thirteen lower teeth are present, along with an additional poorly preserved isolated tooth

146 between the tenth and eleventh in-place teeth, which may be either a disarticulated upper or

147 lower tooth. The teeth are set within alveoli along a continuous groove. No distinct bony septa

148 between alveoli are visible but may be present at the bottom of the dental groove, being

149 concealed in matrix that is very difficult to remove through mechanical preparation. The roots of

150 some teeth are clearly expanded at the base and exhibit plications that are coarser than crown

151 striation. The most anterior tooth is completely exposed anteriorly, revealing its root structure

152 inside the dental groove. It is seen there that the root ceases its expansion once inside the

153 groove, and teeth are embedded to both the labial wall and the base of the groove. A narrow gap

154 emerges between the lingual wall and the root toward the dentigerous margin. Tooth

155 implantation is likely subthecodont (sensu Motani, 1997a), although histological study is

156 necessary to firmly establish this. The root cross-section is much wider than long, as reported for

157 Utatsusaurus hataii (Motani, 1996).

158

159 Teeth are isodont and conical with striated crowns. Tooth roots are extensively exposed above

160 the alveolar margin such that they account for half or more of the exposed height of each tooth. 
161 Tooth crowns are distinguished from these exposed roots by a distinct margin, with most crowns

162 slightly constricted at their base. Some crowns exhibit slightly higher convexity of their anterior

163 surface relative to the posterior surface given them a slightly recurved appearance. The teeth are

164 also recurved lingually toward the tip, as clearly seen in the most anterior tooth (Fig 2B). This

165 curvature closely resembles what was described for Utatsusaurus hataii (Motani, 1996:Fig. 3;

166 Cuthbertson et al., 2013a:Fig 7C, D). The tips of the teeth are relatively blunt. Tooth crowns are

167 approximately $3.6 \mathrm{~mm}$ tall and $2 \mathrm{~mm}$ in mesiodistal diameter. Spacing between teeth ranges from

$1683 \mathrm{~mm}$ to $6 \mathrm{~mm}$, more widely spaced teeth may have replacement teeth between them. One 10

169 mm gap along the tooth row likely represents at least one missing tooth. Several teeth are broken,

170 either at the root or the crown, revealing a pulp cavity without evidence of infolding of the

171 dentine.

172

173 Remarks. The tooth morphology observed in this specimen closely resembles that described for

174 Utatsusaurus hataii from the Lower Triassic Osawa Formation of Kitakami, Japan (Shikama et

175 al., 1978). Most notably, the teeth curve lingually and slightly posteriorly toward the tip, which is

176 a feature that is uniquely known in Utatsusaurus among basal ichthyopterygians. Other shared

177 features include: isodont dentition, tall exposed roots, blunt conical striated crowns, a slightly

178 constricted base of some crowns, and an absence of infolding in the pulp cavity. Each of these

179 features is observed in the holotype of Utatsusaurus hataii (IGPS 95941) (Motani, 1996) and

180 most are reported in a referred specimen (UHR 30691) (Cuthbertson et al., 2013a). No other

181 Early Triassic or later ichthyopterygian exhibits this suite of dental characters.

182 
183 The teeth of this specimen do diverge from Utatsusaurus hataii in their much larger size. The

184 maximum tooth exposed height in this specimen is $11 \mathrm{~mm}$, whereas the maximum crown height

185 and width are $4.5 \mathrm{~mm}$ and $2.3 \mathrm{~mm}$ respectively (Table 1), compared with $3.3 \mathrm{~mm}, 1.7 \mathrm{~mm}$ and

$1860.9 \mathrm{~mm}$ for the same measurements of teeth in the holotype of Utatsusaurus hataii (Motani,

187 1996). However, the holotype represents a juvenile (Motani, 1997c), so the size difference may

188 partly be explained as ontogenetic variation. A referred specimen (UHR 30691) is somewhat

189 larger than the holotype, however, the teeth of this specimen are still considerably smaller than

190 those of USNM 559349. Despite this difference in size, the overall shape of the teeth in each of

191 these specimens is very similar. Motani (1996) reported "crown shape index" values-calculated

192 as crown height divided by average basal diameter of the tooth crown (Massare, 1987)-ranging

193 between 0.9 and 3.1 with an average value of 1.9 in the type specimen of Utatsusaurus hataii,

194 while these values range from 1.3 to 2.3 with an average of 1.8 in USNM 559349. Likewise, the

195 "crown ratio"-calculated as crown height divided by total exposed tooth height-averages 0.51 in

196 IGPS 95941 and 0.43 in USNM 559349.

197

198 The overall arrangement of bones in the fragmentary mandible is consistent with that observed in

199 the Utatsusaurus holotype (IGPS 94941) and the referred specimen (UHR 30691), notably the

200 long, straight contact between the dentary and surangular. The suture between the surangular and

201 dentary is well developed in IGPS 94941 but indistinct in the larger UHR 30691, possibly a

202 consequence of differing ontogenetic stages, or differential weathering, between these two

203 specimens. USNM 559349 approaches UHR 30691 in that the suture between the dentary and

204 surangular is somewhat obscured, but its approximate course can be traced by a contrast in bone

205 texture and an irregular row of weathered pits. This might suggest a relatively mature individual, 
206 as has been proposed for IGPS 9494, but this is highly speculative given the incomplete nature of

207 the material.

208

209 A partial skull from the Lower Triassic Vega Phroso Member of the Sulphur Mountain

210 Formation from British Columbia, Canada was referred to Utatsusaurus sp. by Nicholls and

211 Brinkman (1993), based largely on the presence of the same dental features detailed above. The

212 teeth of the British Columbia specimen are similar in size to those of the Nevada specimen

213 described here (Nicholls \& Brinkman, 1993) and distinctly larger than those found in the

214 holotype of Utatsusaurus hataii from Japan (Motani, 1996). It is therefore possible that these

215 larger-toothed specimens from the eastern margin of Panthalassa (Nevada, British Columbia)

216 represent a form allied with but distinct from Utatsusaurus hataii; however more complete

217 material is needed before this can be confirmed. Recently, Cuthbertson et al. (2014) described

218 another partial skull from the Vega Phroso Member, which they also referred to Utatsusaurus

219 sp., although they concluded that the material originally referred to this genus by Nicholls and

220 Brinkman (1993) was non-diagnostic at the genus level. Unfortunately this recently described

221 material lacks a lower jaw or teeth and cannot be compared to USNM 559349.

222

223 Ichthyopterygia Owen, 1840

224 cf. Grippiidae Wiman, 1929

225 Definition. The last common ancestor of Grippia longirostris and Gulosaurus helmi, and all its 226 descendants (Ji et al., 2015). 
227 Diagnosis. Maxilla with multiple tooth rows; posterior tooth crown rounded; supratemporal-

228 postorbital contact present; proximal manual phalanges not closely packed proximo-distally

229 (from Ji et al., 2015).

231 Referred specimen. USNM 559350 Partial maxilla including teeth. (Fig. 3)

232 Locality. Fossil Hill, Humboldt Range, Pershing County, Nevada.

233 Horizon and Age. Collected from FH1-5 (Fig. 1) horizon which is Spathian in age based on the

234 occurrence of the ammonoid Prohungarites gutstadi (Guex et al., 2010) and conodonts including

235 Triassospathodus and Neostrachanognathus. This horizon is also characterized by distinctive

236 spherical structures originally interpreted as microbial (i.e. 'oncoids') but more recently

237 suggested to represent sponge "reefs" (Brayard et al., 2011; see further discussion below).

238 Description. USNM 559350 (Fig. 3) is a partial maxilla measuring $20 \mathrm{~mm}$ and bearing five teeth

239 exposed in medial view. The teeth are robust cones exhibiting a trend of posteriorly increasing

240 basal diameter, whereas the crown height remains constant giving the posteriormost preserved

241 tooth a distinctly rounded shape. There is a distinct constriction below the crown separating it

242 from the root below, however the constriction is very slight in the anteriormost tooth. The

243 anteriormost crown height and width are $1.7 \mathrm{~mm}$ and $1.2 \mathrm{~mm}$ respectively; in the second

244 posteriormost tooth, which is better preserved than the posteriormost tooth, crown height and

245 width are $1.3 \mathrm{~mm}$ and $2.1 \mathrm{~mm}$. The tooth enamel appears smooth and polished with little

246 indication of striation; however, this could be attributed to tooth wear. Faint plication is visible

247 on some roots. Although some teeth are abraded, none expose the pulp cavity clearly enough to

248 determine presence or absence of infolded dentine. 
250 In medial view the teeth are attached to the lingual wall of the maxilla, representing pleurodont

251 tooth attachment. An expanded bone of attachment conceals the bases of the two posteriormost

252 teeth, suggesting subleurodont attachement, a modified form of pleurodont attachment (Motani,

253 1997a), in at least the posterior region of the maxillary tooth row. While only a single row of

254 teeth is observed, a shallow depression on the lingual margin of the tooth row immediately

255 anterior to the second posteriormost tooth could represent the attachment facet of a missing

256 tooth. If this were the case it might possibly represent a second row immediately lingual to the

257 preserved teeth. Wide spacing between the four anteriormost teeth would easily accommodate an

258 additional offset tooth row as observed in the maxillary dentition of Grippia (Motani, 1997b) and

259 Gulosaurus (Cuthbertson et al., 2013b).

260

261 Remarks. Among Early Triassic ichthyopterygians, small, robust teeth, similar to those reported

262 here, are typical of the posterior dentition of Grippia (Motani, 1997b). Rounded teeth are also

263 observed in the Early Triassic genus Chaohusaurus (Motani \& You, 1998) and, to a lesser

264 extent, Gulosaurus (Cuthbertson et al. 2013b). Grippia was previously reported from the Lower

265 Triassic Vega Phroso Member of the Sulphur Mountain Formation in British Columbia

266 (Brinkman et al., 1992). This specimen was later redescribed as a distinct taxon, Gulosaurus

267 helmi (Cuthbertson et al., 2013b) and found to be sister taxon to Grippia longirostris. Similarly,

268 recent work by Ji et al. (2015), established a new clade Grippioidea including Grippia,

269 Gulosaurus, Utatsusaurus, and Parvinatator, although the precise relationships among these taxa

270 varied somewhat depending on taxon and character inclusion. The enigmatic marine reptile

271 Omphalosaurus nettarhynchus (Mazin \& Bucher, 1987), previously reported from Spathian

272 lower member of the Prida Formation, also possesses rounded dentition, but is distinct from this 
273 specimen by its much larger size and in exhibiting a broad pavement of rounded teeth on the 274 mandible.

275

276 Alternatively, this specimen may have some affinity with Chaohusaurus, an Early Triassic 277 ichthyopterygian from China in which some specimens also show distinctly rounded posterior 278 dentition (Motani \& You, 1998). However the posterior teeth of Chaohusaurus are generally 279 smaller and more tightly packed than in USNM 559350, averaging approximately ten teeth over $28020 \mathrm{~mm}$ rather than the five teeth observed over the same distance in this specimen.

281 Chaohusaurus was previously regarded as a grippidian partly on the basis of possessing multiple 282 maxillary tooth rows and rounded posterior dentition (Motani, 1999). However, more recent 283 analyses (Cuthbertson et al. 2013b, Ji et al., 2015) do not support this placement. 284

285 The crown shape index in USNM 559350 ranges from 1.0-2.1 and averages 1.4 (Table 1), 286 similar to the average shape index reported for the maxillary dentition of Grippia, 1.4 (Motani, 287 1997b) and Gulosaurus 1.64 (Cuthbertson et al. 2013b). Thus, the rounded dentition observed in 288 USNM 559350 is strongly suggestive of an affinity with some other Early Triassic ichthyopterygians but more precise placement will require more complete skeletal material.

291 Discussion

292 Despite the fragmentary nature of the remains described here, their resemblance with the 293 distinctive dentitions of other Early Triassic ichthyopterygians allows tentative interpretations to 294 be made. The presence of Utatsusaurus-like and Grippia or Chaohusaurus -like forms suggests 295 similarity with the Lower Triassic Vega-Phroso assemblage from the Wapiti Lake region of 
296 British Columbia, from which Utatsusaurus (Nicholls \& Brinkman, 1993; Cuthbertson et al.,

297 2014) and grippidians (Brinkman et al., 1992; Cuthbertson et al., 2013b) have also been reported.

298 However, the type locality of Utatsusaurus is in the Osawa Formation of Japan (Shikama et al.,

299 1978), whereas the type localities of Grippia and Chaohusaurus are in the Vikinghøgda

300 Formation (= "Sticky Keep Formation" of older references) of Spitsbergen (Wiman, 1929, 1933;

301 Hounslow et al., 2008) and the Nanlinghu Formation of Anhui Province, China (Young \& Dong,

302 1972), respectively. Thus, Early Triassic ichthyopterygian taxa were widely distributed around

303 the margins of northern Panthalassa (Cuthbertson et al., 2013b).

304

305 This broad distribution early in their evolutionary history, from numerous Late Spathian

306 (Subcolumbites Zone) localities of broadly coeval age (Scheyer et al., 2014), has made it

307 difficult to pinpoint the biogeographic origins of the group. However, recent work in China has

308 extended the biostratigraphic range of ichthyopterygians to the underlying Procolumbites Zone

309 (Motani et al., 2014; Ji et al., 2014). Furthermore, the occurrence of diverse and endemic

310 hupehsuchians, widely regarded as the ichthyopterygian sister-group, and the plesiomorphic

311 ichthyosauromorph Cartorhynchus (Motani et al., 2015) are consistent with an origin of

312 ichthyopterygians near the south China block in equatorial western Panthalassa.

313

314 The inferred nearshore lifestyle of most Early Triassic ichthyopterygians has led others to

315 propose that these early marine reptiles dispersed along coastlines or across transient

316 epicontinental corridors (Cuthbertson et al., 2013b). However, there is little geological evidence

317 for such corridors in the Early Triassic, which was a time of relatively low global sea level

318 (Miller et al., 2005). Furthermore the absence of Early Triassic ichthyopterygian fossils in 
319 Western Tethys is surprising under this scenario. Conversely, the biogeographic histories of

320 other aquatic-and even terrestrial-reptile groups are marked by occasional transoceanic dispersal

321 events (Rocha et al., 2006; Velez-Juarbe et al., 2007), and such events could explain the

322 distribution of Early Triassic ichthyopteryians on opposite shores of Panthalassa.

323 Brayard et al. (2009) identified trans-Panthalassan distribution patterns in Spathian

324 ammonoids, identifying similar ammonoid faunas in Nevada, Kitakami and British Columbia,

325 which they attributed to oceanographic currents. The occurrence of some Early Triassic marine

326 reptile taxa (e.g. Utatsusaurus) on both the eastern and western margins of of Panthalassa might

327 reflect sporadic crossing of deep ocean basins by these lineages, potentially facilitated by the

328 same ocean currents that mediated transoceanic dispersals of contemporaneous marine

329 invertebrates (Fig. 4). The wide distribution of Early Triassic sauropterygians, including the

330 South China Block (Jiang et al., 2014) and western margin of North America (Storrs, 1991;

331 Lovelace \& Doebbert, 2015) on opposite shores of Panthalassa indicates to a similar dispersal

332 history in the early members of that marine reptile clade. Isolated terranes such as South

333 Kitakami, South Primoyre and Chulitna could have served as stepping-stones for shallow marine

334 taxa. Dispersal along coastlines around the northern margins of Panthalassa remains an

335 alternative scenario that could explain the broad distribution of some Early Triassic

336 ichthyopterygians, with pronounced global warmth in the Early Triassic mediating limiting

337 climatic conditions at high latitudes (Sun et al., 2012). However, the apparent absence of

338 ichthyopterygian fossils from high latitudes on the western margin of northern Panthalassa

339 remains a puzzle under this scenario. 
341 Intriguingly, the oldest marine reptile bearing horizons at Fossil Hill are associated with a

342 prominent limestone marker bed bearing distinctive spherical structures $\sim 1-2 \mathrm{~cm}$ in diameter

343 (Fig. 5). We initially interpreted these structures as microbial 'oncoids.' Widespread

344 microbialite-dominated facies are characteristic of Lower Triassic strata globally, including in

345 the western United States (Pruss \& Bottjer, 2004; Baud et al., 2007), and are interpreted as a

346 byproduct of the end-Permian mass extinction and subsequent delayed biotic recovery of

347 metazoan reefs (Pruss et al., 2004). A similar association between the basal sauropterygian

348 Corosaurus and stromatolites in the Lower Triassic Alcova limestone has been reported

349 previously (Storrs, 1991). More recently, similar spheroidal structures from the Humboldt Range

350 and other localities in western North America have been interpreted as 'transient sponge reefs'

351 (Brayard et al., 2011). Thus, the diversification and dispersal of Early Triassic marine reptiles

352 was apparently well underway at the end of the Early Triassic (Scheyer et al., 2014) despite some

353 lingering signs of continued environmental stress preserved in the same strata. Future work at

354 this new locality, and elsewhere, may help to clarify the role that large-scale environmental

355 changes played in shaping the early evolutionary history of Mesozoic marine reptiles.

356

357 Acknowledgements

358 We thank Tetsuya Sato for assistance with preparation of USNM 559349. Torsten Scheyer, Lars

359 Schmitz, and Cheng Ji all provided helpful discussion. Reviewers Robin Cuthbertson and Nadia

360 Fröbisch and the handling editor also provided critiques and suggestions that greatly improved

361 this paper.

362

363 References 
364 Baud,A., Richoz, S., and Pruss, S. 2007. The Lower Triassic anachronistic carbonate facies in

365

366

367

368

369

370

371

372

373

374

375

376

377

378

379

380

381

382

383

384

space and time. Global and Planetary Change, 55:81-89.

DOI:10.1016/j.gloplacha.2006.06.008

Brayard, A., Escarguel, G., Bucher, H., and Brühwiler, T. 2009. Smithian and Spathian (Early Triassic) ammonoid assemblages from terranes: paleoceanographic and paleogeographic implications. Journal of Asian Earth Sciences, 36:420-433.

DOI:10.1016/j.jseaes.2008.05.004

Brayard, A., Vennin, E., Olivier, N., Bylund, K. G., Jenks, J., Stephen, D. A., Bucher H., Hofmann, R., Goudemand, and N., Escarguel, G. 2011. Transient metazoan reefs in the aftermath of the end-Permian mass extinction. Nature Geoscience, 4:693-697. DOI:10.1038/ngeo1264

Brinkman, D. B., Xijin, Z. H. A. O., and Nicholls, E. L. 1992. A primitive ichthyosaur from the Lower Triassic of British Columbia, Canada. Palaeontology, 35:465-474.

Camp, C. L. 1976. Vorläufige Mitteilung über große Ichthyosaurier aus der oberen Trias von Nevada. Sitzungsberichte der Österreichischen Akademie der Wissenschaften, Mathematisch-naturwissenschaftliche Klasse, Abteilung I,185:125-134.

Camp, C. L. 1980. Large ichthyosaurs from the Upper Triassic of Nevada. Palaeontographica Abteilung A 170:139-200.

Case, E. C. 1936. A nothosaur from the Triassic of Wyoming. University of Michigan Contributions from the Museum of Paleontology 5:1-36.

Cuthbertson, R. S., Russell, A. P., and Anderson, J. S. 2013a. Reinterpretation of the cranial 
morphology of Utatsusaurus hataii (Ichthyopterygia) (Osawa Formation, Lower Triassic, Miyagi, Japan) and its systematic implications. Journal of Vertebrate Paleontology, 33:817-830. DOI:10.1080/02724634.2013.756495

388

389

Cuthbertson, R. S., Russell, A. P., and Anderson, J. S. 2013b. Cranial morphology and relationships of a new grippidian (Ichthyopterygia) from the Vega-Phroso Siltstone Member (Lower Triassic) of British Columbia, Canada. Journal of Vertebrate Paleontology, 33:831-847. DOI:10.1080/02724634.2013.755989

Cuthbertson, R. S., Russell, A., and Anderson, J. 2014. The first substantive evidence of Utatsusaurus (Ichthyopterygia) from the Sulphur Mountain Formation (Lower-Middle Triassic) of British Columbia, Canada: a skull roof description with comparison to other early taxa. Canadian Journal of Earth Sciences, 51:180-185. DOI: 10.1139/cjes-20130185

Fröbisch, N. B., Sander, P., and Rieppel, O. 2006. A new species of Cymbospondylus (Diapsida, Ichthyosauria) from the Middle Triassic of Nevada and a re-evaluation of the skull osteology of the genus. Zoological Journal of the Linnean Society, 147:515-538. DOI: 10.1111/j.1096-3642.2006.00225.x

Fröbisch, N. B., Fröbisch, J., Sander, P. M., Schmitz, L., and Rieppel, O. 2013. Macropredatory ichthyosaur from the Middle Triassic and the origin of modern trophic networks. Proceedings of the National Academy of Sciences, 110:1393-1397. DOI: 10.1073/pnas. 1216750110

Guex, J., Hungerbühler, A., Jenks, J.F., O'Dogherty, L., Atudorei, V.,Taylor, D.G., Bucher, H. and Bartolini, A. 2010. Spathian (Lower Triassic) ammonoids from western USA (Idaho, California, Utah and Nevada). Mémoires de Géologie (Lausanne), 49. 
408 Hounslow, M. W., Peters, C., Mørk, A., Weitschat, W., and Vigran, J. O. 2008.

409 Biomagnetostratigraphy of the Vikinghøgda Formation, Svalbard (Arctic Norway), and

410 the geomagnetic polarity timescale for the Lower Triassic.Geological Society of America

$411 \quad$ Bulletin, 120:1305-1325. DOI: 10.1130/B26103.1

412 Ji, C., Jiang, D., Motani, R., Rieppel, O., Hao, W., and Sun, Z. 2015. Phylogeny of the

413 Ichthyopterygia incorporating the recent discoveries from South China. Journal of

$414 \quad$ Vertebrate Paleontology. e1025956 DOI: 10.1080/02724634.2015.1025956

415 Ji, C, C. Zhang, D. Jiang, H. Bucher, R. Motani, and A. Tintori 2014. Ammonoid age control of

416 the Early Triassic marine reptile from Chaohu. Paleoworld. Available online 8 December

417 2014. DOI: 10.1016/j.palwor.2014.11.009

418 Jiang, D., Motani, R., Tintori A., Rieppel O., Chen G., Huang J., Zhang R., Sun, Z. and Ji, C. 2014. The Early Triassic Eosauropterygian Majiashanosaurus discocoracoidis, Gen. Et Sp. Nov. (Reptilia, Sauropterygia), from Chaohu, Anhui Province, People's Republic of

422 China. Journal of Vertebrate Paleontology, 34(5): 1044-1052. DOI:

423

Leidy, J. 1868. Notice of some reptilian remains from Nevada. Proceedings of the Academy of 424 Natural Sciences of Philadelphia 109:177-178.

425

426

427

428

429

430

$10.1080 / 02724634.2014 .846264 \square$

Lovelace, D. M., and Doebbert, A. C. 2015. A new age constraint for the Early Triassic Alcova Limestone (Chugwater Group), Wyoming. Palaeogeography, Palaeoclimatology, Palaeoecology, 424:1-5. DOI: 10.1016/j.palaeo.2015.02.009

Massare, J. A. (1987). Tooth morphology and prey preference of Mesozoic marine reptiles. Journal of Vertebrate Paleontology, 7:121-137. DOI: 10.1080/02724634.1987.10011647 Massare, J. A., and Callaway, J. M. 1994. Cymbospondylus (Ichthyosauria: Shastasauridae) from 
the Lower Triassic Thaynes Formation of southeastern Idaho. Journal of Vertebrate Paleontology, 14:139-141. DOI: 10.1080/02724634.1994.10011545

433 434

Mazin, J. M., and Bucher, H. 1987. [Omphalosaurus nettarhynchus, une nouvelle espèce d'Omphalosauridé (Reptilia, Ichthyopterygia) du Spathien de la Humboldt Range (Nevada, USA)]. Comptes rendus de l'Académie des sciences. Série 2, Mécanique, Physique, Chimie, Sciences de l'univers, Sciences de la Terre, 305:823-828. [French with English Abstract]

McGowan, C., and Motani., R. 2003. Part 8. Ichthyopterygia; in H.-D. Sues (ed.), Handbook of Paleoherpetology. Verlag Dr. Friedrich Pfeil, Munich.

Merriam, J. C. 1905. A primitive ichthyosaurian limb from the Middle Triassic of Nevada. University of California Publications. Bulletin of the Department of Geology, 4:33-38.

Merriam, J. C. 1906. Preliminary note on a new marine reptile from the Middle Triassic of Nevada. University of California Publications, Bulletin of the Department of Geology $5: 75-79$

Merriam, J. C. 1908. Triassic Ichthyosauria, with special reference to the American forms. Memoirs of the University of California 1:1-196

Merriam, J. C. 1910. The skull and dentition of a primitive ichthyosaurian from the Middle Triassic. University of California Publications, Bulletin of the Department of Geology 5:381-390.

Miller, K.G., Kominz, M.A., Browning, J.V., Wright, J.D., Mountain, G.S., Katz, M.E., Sugarman, P.J., Cramer, B.S., Christie-Blick, N. and Pekar, S.F., 2005. The Phanerozoic record of global sea-level change. Science, 31:1293-1298.

Motani, R. 1996. Redescription of the dental features of an Early Triassic ichthyosaur, 
Utatsusaurus hataii. Journal of Vertebrate Paleontology, 16:396-402. DOI:

455 $10.1080 / 02724634.1996 .10011329$

456 457

Motani, R. 1997a. Temporal and spatial distribution of tooth implantation in ichthyosaurs; pp. 81-103 in Callaway, J. M. and E. L. Nicholls (eds.), Ancient Marine Reptiles. Academic Press, London and New York.

Motani, R. 1997b. Redescription of the dentition of Grippia longirostris (Ichthyosauria) with a comparison with Utatsusaurus hataii. Journal of Vertebrate Paleontology, 17:39-44. DOI: $10.1080 / 02724634.1997 .10010951$

Motani, R. 1997c. New information on the forefin of Utatsusaurus hataii (Ichthyosauria). Journal of Paleontology 71:475-479.

Motani, R. 1999. Phylogeny of the Ichthyopterygia. Journal of Vertebrate Paleontology, 19:473496. DOI: $10.1080 / 02724634.1999 .10011160$

Motani, R., Jiang, D.Y., Chen, G.B., Tintori, A., Rieppel, O., Ji, C. and Huang, J.D., 2015. A basal ichthyosauriform with a short snout from the Lower Triassic of China. Nature, 517:485-488. DOI: 10.1038/nature13866

Motani, R. and You, H. 1998. Taxonomy and limb ontogeny of Chaohusaurus geishanensis (Ichthyosauria), with a note on the allometric equation. Journal of Vertebrate Paleontology 18:533-540. DOI: 10.1080/02724634.1998.10011080

Nicholls, E. L., and Brinkman, D. 1993. A new specimen of Utatsusaurus (Reptilia: Ichthyosauria) from the Lower Triassic Sulphur Mountain Formation of British Columbia. Canadian Journal of Earth Sciences, 30:486-490. DOI: 10.1139/e93-037

Nicholls, E. L., and Brinkman, D. B. 1995. A new ichthyosaur from the Triassic Sulphur 
476

477

478

479

480

481

482

483

484

485

486

487

488

489

490

491

492

493

494

495

496

497

Mountain formation of British Columbia; pp. 521-535 in W. A. S. Sarjeant

(ed.), Vertebrate Fossils and the Evolution of Scientific concepts. Gordon and Breach, Switzerland.

Nichols, K. M., and Silberling, N. J. 1977. Stratigraphy and depositional history of the Star Peak Group (Triassic), northwestern Nevada (Vol. 178). Geological society of America.

Orchard, M.J. 1995. Taxonomy and correlation of Lower Triassic (Spathian) segminate conodonts from Oman and revision of some species of Neospathodus. Journal Paleontology, 69: 110-122. DOI: 10.1017/S0022336000026962

Owen, R. 1840. Report on British fossil reptiles. Part I. Report of the British Association for the Advancement of Science, Plymouth,9: 43-126.

Rocha, S., Carretero, M. A., Vences, M., Glaw, F., and James Harris, D. (2006). Deciphering patterns of transoceanic dispersal: the evolutionary origin and biogeography of coastal lizards (Cryptoblepharus) in the Western Indian Ocean region. Journal of Biogeography, 33(1), 13-22. DOI: 10.1111/j.1365-2699.2005.01375.x

Pruss, S. B., and Bottjer, D. J. 2004. Late Early Triassic microbial reefs of the western United States: a description and model for their deposition in the aftermath of the end-Permian mass extinction. Palaeogeography, Palaeoclimatology, Palaeoecology, 211:127-137. DOI: $10.1016 /$ j.palaeo.2004.05.002

Sander, P. M., Rieppel, O. C., and Bucher, H. 1994. New marine vertebrate fauna from the Middle Triassic of Nevada. Journal of Paleontology, 68:676-680. DOI: $10.1017 / \mathrm{S} 0022336000026020$

Sander, P. M., Rieppel, O. C., and Bucher, H. 1997. A new pistosaurid (Reptilia: Sauropterygia) 
498

499

500

501

502

503

504

505

506

507

508

509

510

511

512

513

514

515

516

517

518

519

520

from the Middle Triassic of Nevada and its implications for the origin of the

plesiosaurs. Journal of Vertebrate Paleontology, 17:526-533. DOI:

$10.1080 / 02724634.1997 .10010999$

Scheyer, T. M., Romano, C., Jenks, J., and Bucher, H. 2014. Early Triassic Marine Biotic Recovery: The Predators' Perspective. PloS one, 9(3). DOI:

10.1371/journal.pone.0088987

Schmitz, L., Sander, P. M., Storrs, G. W., and Rieppel, O. 2004. New Mixosauridae

(Ichthyosauria) from the Middle Triassic of the Augusta Mountains (Nevada, USA) and

their implications for mixosaur taxonomy.Palaeontographica, Abteilung A, 270:133-162.

DOI: $10.1073 /$ pnas.1216750110

Shikama, T., Kamei, T., and Murata, M. 1978. Early Triassic Ichthyosaurus, Utatsusaurus hataii gen. et sp. nov., from the Kitakami massif, Northeast Japan. Science Reports of the Tohoku University, Sendai, Second Series (Geology), 48:77-97.

Silberling, N. J. 1962. Stratigraphic distribution of Middle Triassic Ammonites at Fossil Hill, Humboldt Range, Nevada. Journal of Paleontology, 153-160.

Storrs, G. W. 1991. Anatomy and relationships of Corosaurus alcovensis (Diapsida: Sauropterygia) and the Triassic Alcova Limestone of Wyoming. Peabody Museum of Natural History, Yale University.

Sun, Y., Joachimski, M. M., Wignall, P. B., Yan, C., Chen, Y., Jiang, H., ... \& Lai, X. (2012). Lethally hot temperatures during the Early Triassic greenhouse. Science, 338: 366-370.

Vélez-Juarbe, J., Brochu, C. A., and Santos, H. 2007. A gharial from the Oligocene of Puerto Rico: transoceanic dispersal in the history of a non-marine reptile. Proceedings of the Royal Society B: Biological Sciences, 274:1245-1254. DOI: 10.1098/rspb.2006.0455 
521 Wiman, C. 1929. Eine neue Reptilien-Ordnung aus der Trias Spitzbergens. Bulletin of the

522 Geological Institution of the University of Upsala 22: 183-196.

523 Wiman, C. 1933. Uber Grippia longirostris. Nova Acta Regiae Societatis Scientiarum

$524 \quad$ Upsaliensis, ser. 4, 9: 1-19.

525 Wyld, S. J. 2000. Triassic evolution of the arc and backarc of northwestern Nevada, and

526 evidence for extensional tectonism. Special Papers Geological Society of America:185$527 \quad 208$.

528 Young, C. C., and Dong, Z. M. 1972. Chaohusaurus geishanensis from Anhui

529 Province. Academia Sinica, Institute of Vertebrate Paleontology and Palaeoanthropology, $530 \quad$ Memoir, 9:11-14. 
Figure 1 (on next page)

Summarized stratigraphy and regional map

(A) Stratigraphy of the Triassic Prida Formation near Fossil Hill in the Humboldt Range, Nevada indicating horizons of specimens USNM 559349 and 559350 and conodont samples. (B) Regional map, modified from Silberling (1962). 


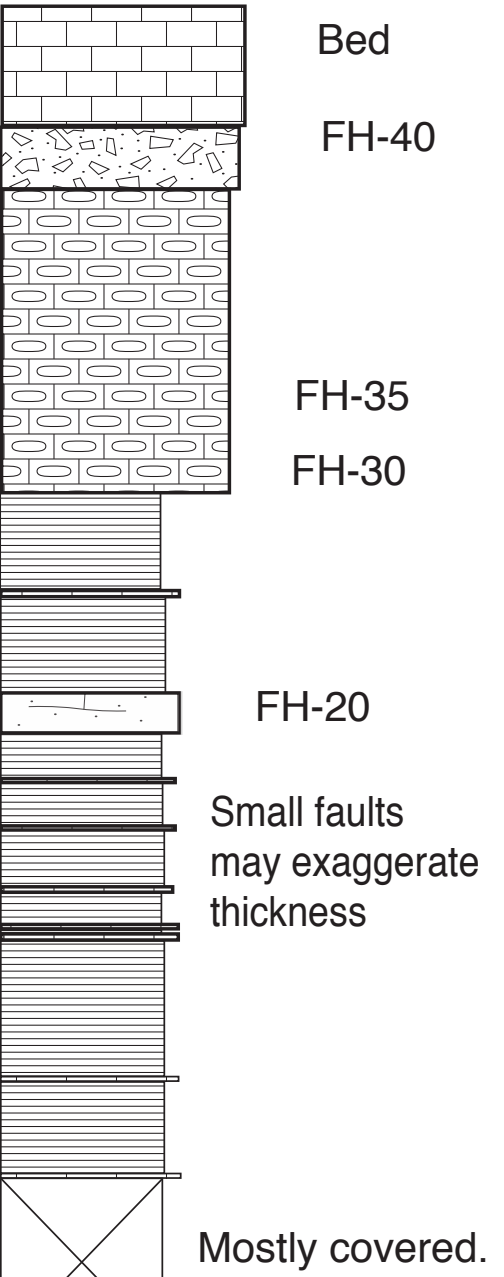

Manuscriptto be reviewed

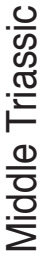
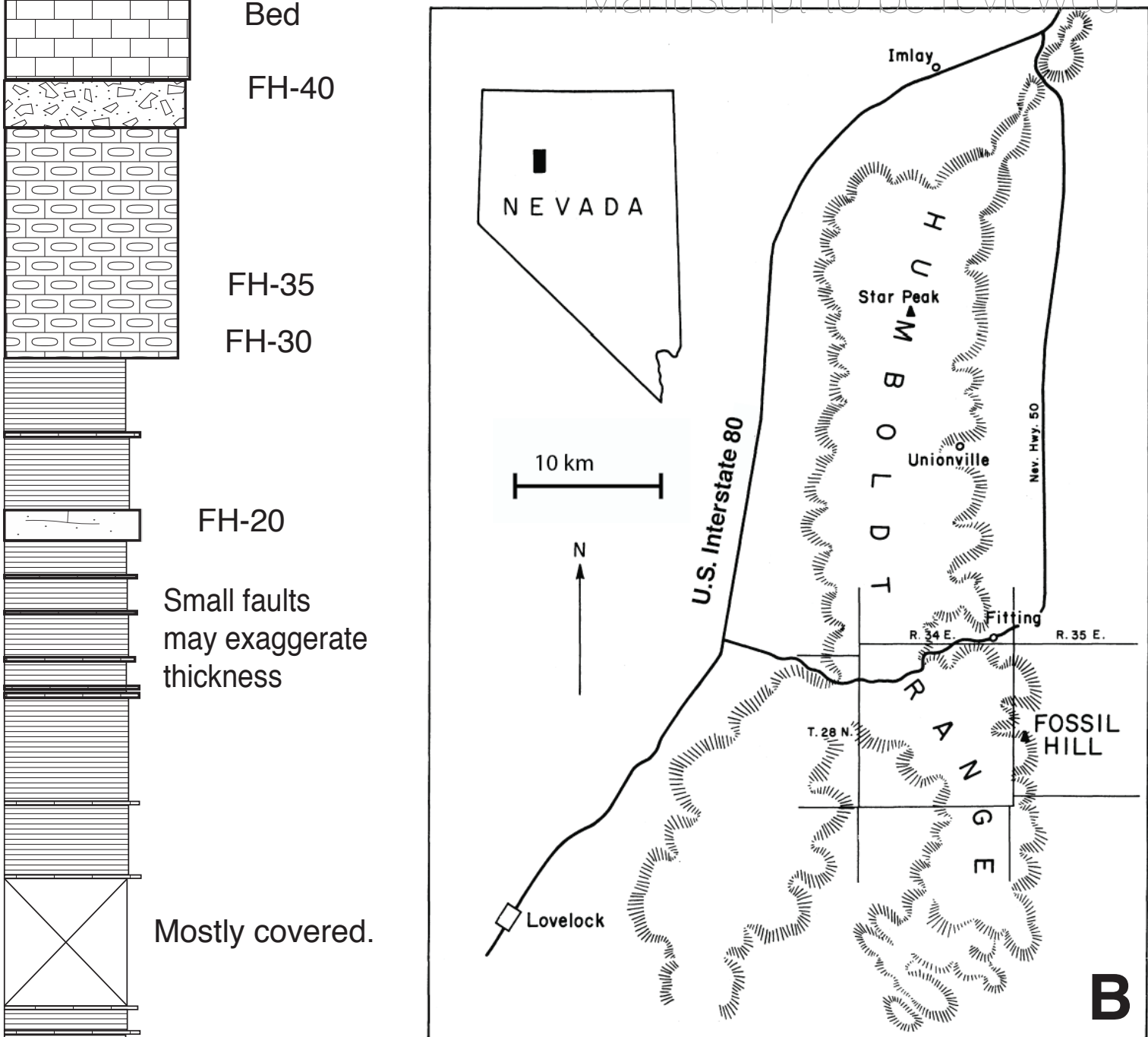

Stor Peok

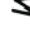

$\infty$

衰 
2

Specimen USNM 559349, partial ichthyopterygian jaw cf. Utatsusaurus.

(A) Complete specimen, in labial view, anterior to the left. Squares on scale bar equal $5 \mathrm{~mm}$.

(B) Magnified view of anterior dentition, squares on scale bar equal $1 \mathrm{~mm}$. 

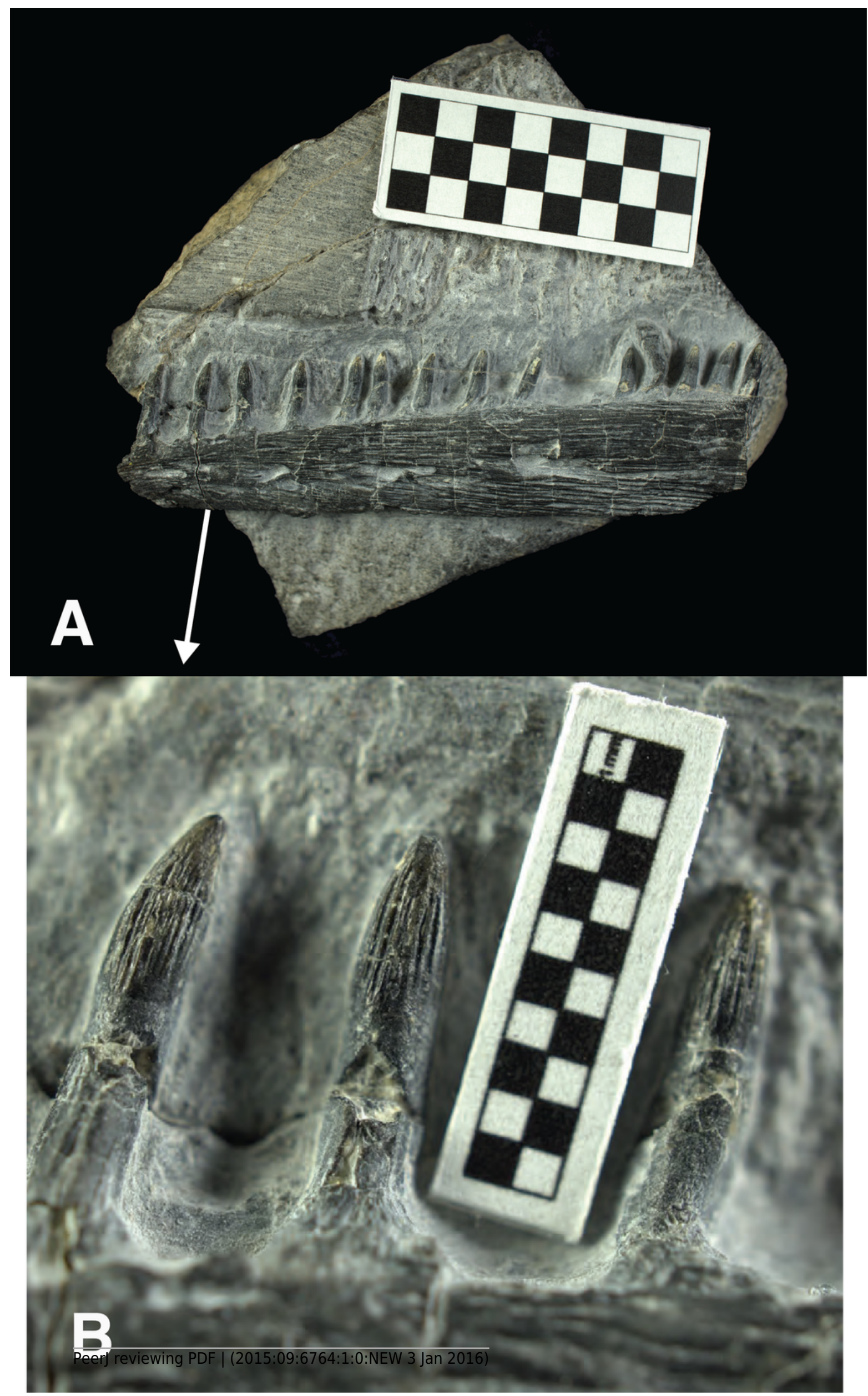
3

USNM 559350 Partial ichthyopterygian maxilla cf. Grippidia.

A) Partial maxilla in lingual view, anterior to the left. Squares on scale bar equal $1 \mathrm{~mm}$. White arrow indicates possible attachment facet for tooth in second lingual tooth row. B) Magnified view of dentition. 


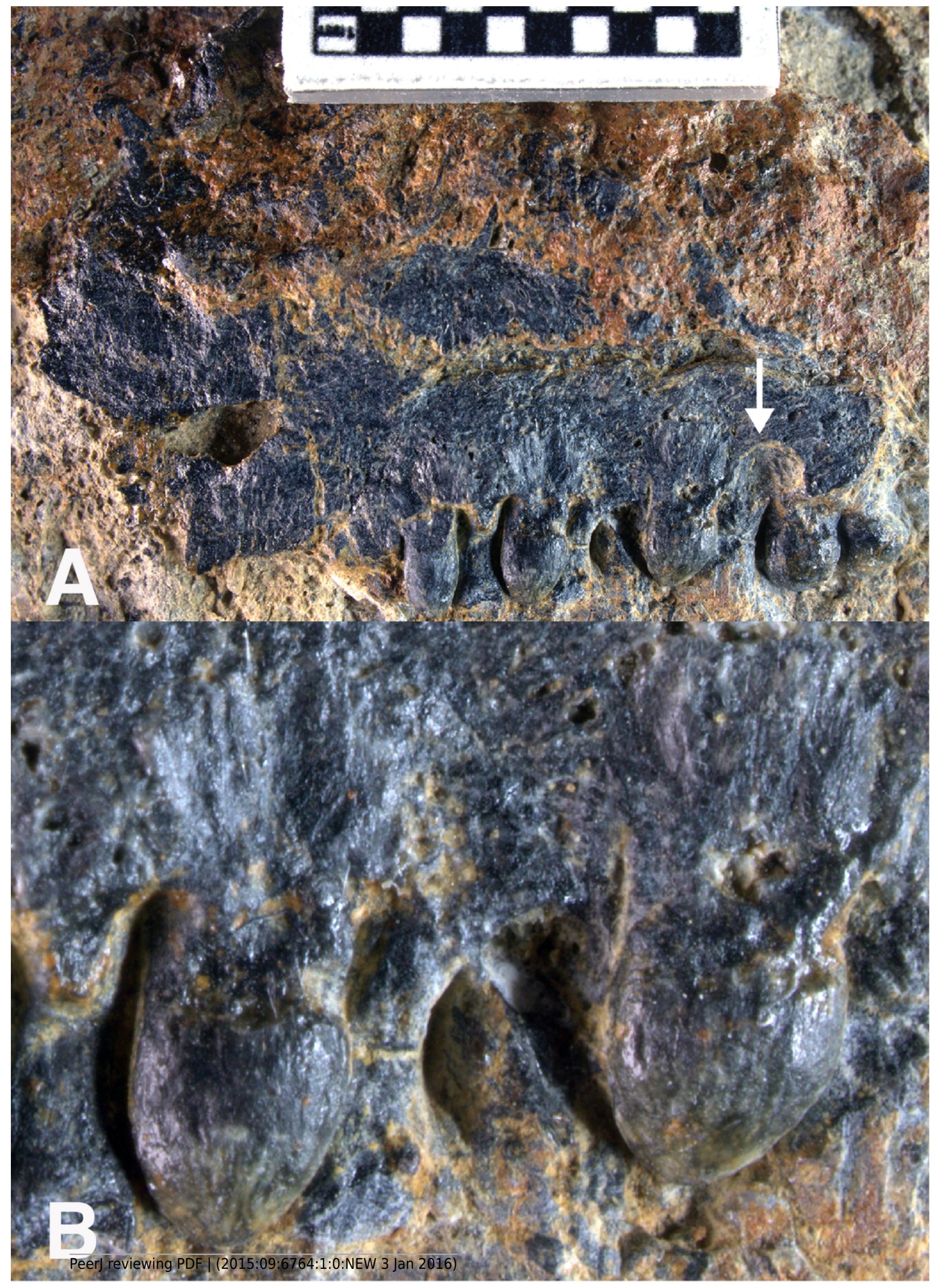


Figure 4 (on next page)

Distribution of Early Triassic ichthyopterygians.

Paleogeographic distribution of Early Triassic ichthyopterygians, map modified from Brayard et al. (2009). Locality abbreviations as follows: (B) British Columbia; (C) South China; (I) Idaho; (K) South Kitakami; (N) Nevada (present study, highlighted in yellow); (S) Spitsbergen;

(T) Timor. Arrows indicate inferred ammonoid dispersal routes (Brayard et al., 2009) 


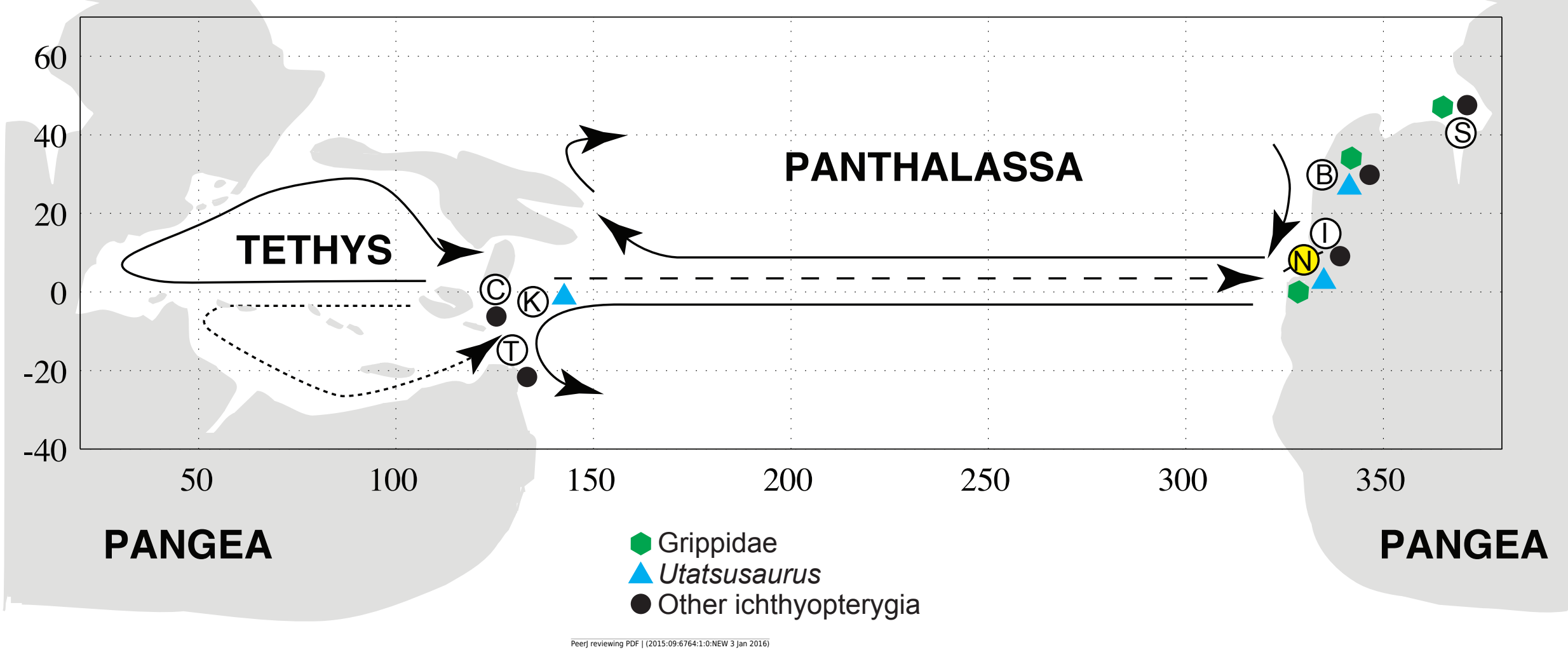




\section{5}

Distinctive sedimentary structures associated with horizon of USNM 559350

Spherical structures in FH1-5 that may represent microbial structures or sponges. This appears to be a widespread and distinctive regional Lower Triassic facies associated with recovery from the end-Permian mass-extinction. Vertebrate fossils also occur in this horizon including USNM 559350 described here. Hammer for scale is approximately $30 \mathrm{~cm}$ in length.

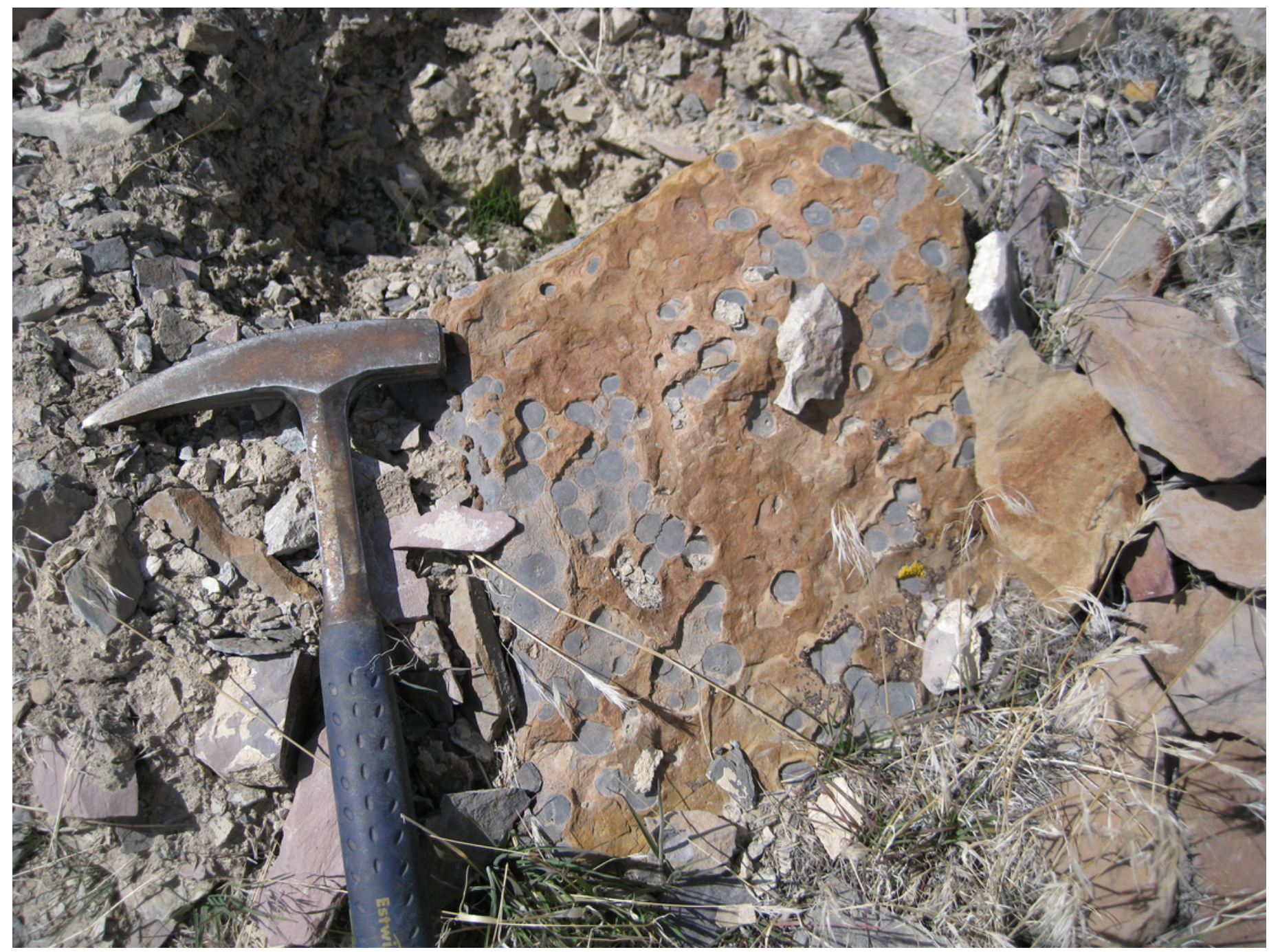




\section{Table $\mathbf{1}$ (on next page)}

Summarized tooth measurements from USNM 559349 and USNM 559350.

All measurements in mm except for shape index and crown ratio, which are ratios. 
Specimen

USNM 559349 Max.

Min.

Mean

USNM 559350

Max.

Min.

Mean
Proxmial Exposed Crown Crown Crown width height width height shape Crown $(\mathrm{mm})^{\mathrm{a}} \quad(\mathrm{mm})^{\mathrm{b}} \quad(\mathrm{mm})^{\mathrm{c}} \quad(\mathrm{mm})^{\mathrm{d}} \quad$ index $^{\mathrm{e}} \quad$ ratio $^{\mathrm{f}}$

4.211.

2.5

3.2

6.4

2.3

4.5

2.3

0.51

1.9

2.7

1.3

0.39

8.5

2.1

3.6

1.8

0.43

$\begin{array}{ll}1.6 & 2.5\end{array}$

2.1

1.7

$2.1 \quad 0.88$

$1.0 \quad 1.8$

1.2

1.1

$1.0 \quad 0.61$

1.4

1.6

1.5

1.4

0.69

1

a Measured as mesio-distal width of the root at the jawline, following Motani (1996).

b Measured as distance from tip of crown to jaw margin.

${ }^{c}$ Measured as mesio-distal width of the crown at its widest point.

d Base of crown is distinctive in USNM 559349 due to crown ornamentation; base of crown in USNM 559350 is less distinct but can be approximated by slight basal constriction.

e Calculated as crown height/crown width, following Massare (1987).

${ }^{\mathrm{f}}$ Calculated as crown height/exposed tooth height, following Motani (1996). 